Objectives: To evaluate the efficacy of upadacitinib (UPA) in subgroups of patients with PsA with a low (baseline swollen joint count [SJC] <5) or high (SJC 25) SJC (LSJ or HSJ).

Methods: Data were pooled across the SELECT-PsA $1^{1}$ (non-biologic disease-modifying antirheumatic drug [non-bDMARD] inadequate response [IR] or intolerance) and SELECT-PsA $2^{2}$ (bDMARD IR or intolerance) trials, which both enrolled patients with $\geq 3$ involved joints ( $S J C \geq 3$ and tender joint count $[T J C] \geq 3$ ). Subgroup analysis was performed for patients with LSJ or HSJ treated with UPA $15 \mathrm{mg}$ once daily (QD) or placebo (PBO). Efficacy endpoints included minimal disease activity (MDA), very low disease activity (VLDA), Psoriatic Arthritis Disease Activity Score (PASDAS) low disease activity (LDA; $\leq 3.2$ ), PASDAS remission ( $\leq 1.9$ ), and $20 / 50 / 70 \%$ improvement in American College of Rheumatology (ACR) criteria (ACR20/50/70), all at Week 24, and Psoriasis Area Severity Index (PASI) 75 and static Investigator Global Assessment of Psoriasis (sIGA) 0/1 at Week 16.

Results: At baseline, patients with HSJ $(n=1060)$ had similar demographic characteristics but tended to have higher overall disease activity than patients with LSJ across multiple disease domains $(n=215$; Table 1). UPA efficacy appeared comparable in patients with LSJ and HSJ, with similar proportions of patients achieving composite (MDA, VLDA, PASDAS LDA, and PASDAS remission) measures at Week 24, and skin endpoints (PASI 75 and SIGA 0/1) at Week 16 (Figure 1). At Week 24, 60.0/36.8/22.1\% of patients with LSJ receiving UPA $15 \mathrm{mg}$ achieved ACR20/50/70 vs $40.0 / 17.5 / 5.8 \%$ in the PBO group; rates were $70.3 / 49.7 / 26.2 \%$ (UPA $15 \mathrm{mg}$ ) and $36.1 / 15.3 / 3.3 \%$ (PBO) in those with HSJ.

Table 1. Baseline characteristics

\begin{tabular}{|c|c|c|c|c|c|c|}
\hline & \multicolumn{2}{|l|}{ PBO } & \multicolumn{2}{|c|}{ UPA $15 \mathrm{mg}$ QD } & \multicolumn{2}{|l|}{ Total } \\
\hline & $\begin{array}{l}\text { LSJ } \\
n=120\end{array}$ & $\begin{array}{l}\text { HSJ } \\
n=515\end{array}$ & $\begin{array}{l}\text { LSJ } \\
\mathrm{n}=95\end{array}$ & $\begin{array}{l}\text { HSJ } \\
n=545\end{array}$ & $\begin{array}{l}\text { LSJ } \\
\mathrm{n}=215\end{array}$ & $\begin{array}{l}\text { HSJ } \\
n=1060\end{array}$ \\
\hline Female, n (\%) & $65(54.2)$ & $266(51.7)$ & $49(51.6)$ & $302(55.4)$ & $114(53.0)$ & $568(53.6)$ \\
\hline $\begin{array}{l}\text { Age (years) } \\
\text { mean (SD) }\end{array}$ & $52.2(12.7)$ & $51.5(12.0)$ & $52.0(10.6)$ & $52.0(12.4)$ & $52.1(11.8)$ & $51.8(12.2)$ \\
\hline $\begin{array}{l}\text { Duration since } \\
\text { PsA symp- } \\
\text { toms (years), } \\
\text { mean (SD) }\end{array}$ & $10.5(9.2)$ & $11.1(10.2)$ & $9.8(8.2)$ & $10.3(8.9)$ & $10.2(8.7)$ & $10.7(9.6)$ \\
\hline $\begin{array}{l}\text { BMI, mean } \\
\quad(S D)\end{array}$ & $29.7(6.3)$ & $31.1(7.2)$ & $29.8(6.2)$ & $30.7(6.9)$ & $29.7(6.2)$ & $30.9(7.0)$ \\
\hline \multicolumn{7}{|c|}{ Prior failed bDMARDs, n (\%) } \\
\hline 0 & $3(2.5)$ & $15(2.9)$ & $1(1.1)$ & $15(2.8)$ & $4(1.9)$ & $30(2.8)$ \\
\hline 1 & $22(18.3)$ & $113(21.9)$ & $22(23.2)$ & $104(19.1)$ & $44(20.5)$ & $217(20.5)$ \\
\hline 2 & $4(3.3)$ & $31(6.0)$ & $7(7.4)$ & $28(5.1)$ & $11(5.1)$ & $59(5.6)$ \\
\hline$\geq 3$ & $4(3.3)$ & $20(3.9)$ & $7(7.4)$ & $27(5.0)$ & $11(5.1)$ & $47(4.4)$ \\
\hline $\begin{array}{l}\text { Use of } \geq 1 \\
\text { non-bD- } \\
\text { MARD at }\end{array}$ & $87(72.5)$ & $360(69.9)$ & $63(66.3)$ & $388(71.2)$ & $150(69.8)$ & $748(70.6)$ \\
\hline \multicolumn{7}{|c|}{ baseline, n (\%) } \\
\hline $\begin{array}{l}\text { Dactylitis (LDI } \\
>0), \mathrm{n}(\%)\end{array}$ & $21(17.5)$ & $169(32.8)$ & $15(15.8)$ & $176(32.3)$ & $36(16.7)$ & $345(32.5)$ \\
\hline $\begin{array}{c}\text { Enthesitis (LEI } \\
>0), \mathrm{n}(\%)\end{array}$ & $60(50.0)$ & $325(63.1)$ & $60(63.2)$ & $343(62.9)$ & $120(55.8)$ & $668(63.0)$ \\
\hline $\begin{array}{l}\text { TJC68, mean } \\
\text { (SD) }\end{array}$ & $12.5(11.3)$ & $23.9(15.8)$ & $14.6(13.5)$ & $23.1(15.8)$ & $13.4(12.3)$ & $23.5(15.8)$ \\
\hline $\begin{array}{l}\text { SJC66, mean } \\
\text { (SD) }\end{array}$ & $3.5(0.5)$ & $13.2(8.3)$ & $3.6(0.5)$ & $12.9(9.0)$ & $3.6(0.5)$ & $13.0(8.7)$ \\
\hline $\begin{array}{l}\text { HAQ-DI, mean } \\
\text { (SD) }\end{array}$ & $1.0(0.6)$ & $1.2(0.7)$ & $0.9(0.6)$ & $1.2(0.6)$ & $0.9(0.6)$ & $1.2(0.7)$ \\
\hline $\begin{array}{r}\text { hs-CRP > ULN } \\
(\mathrm{mg} / \mathrm{L}), \mathrm{n}(\%)\end{array}$ & $82(68.3)$ & $363(70.5)$ & $62(65.3)$ & $388(71.2)$ & $144(67.0)$ & $751(70.8)$ \\
\hline $\begin{array}{l}\text { BSA-Ps, median } \\
\text { (range) }\end{array}$ & $\begin{array}{l}n 3.0 \\
(0.1-70.0)\end{array}$ & $\begin{array}{l}4.0 \\
(0.1-95.0)\end{array}$ & $\begin{array}{l}2.0 \\
(0.1-80.0)\end{array}$ & $\begin{array}{l}3.0 \\
(0.1-97.0)\end{array}$ & $\begin{array}{l}3.0 \\
(0.1-80.0)\end{array}$ & $3.0(0.1-97.0)$ \\
\hline $\begin{array}{l}\text { BSA-PS } \geq 3 \% \\
n(\%)\end{array}$ & 57 (47.5) & $285(55.3)$ & $44(46.3)$ & $300(55.0)$ & $101(47.0)$ & $585(55.2)$ \\
\hline $\begin{array}{l}\text { PASI (baseline } \\
\text { BSA-PS } \geq \\
\text { 3\%), mean } \\
\text { (SD) }\end{array}$ & $7.7(7.5)$ & $12.1(11.9)$ & $8.2(7.0)$ & $10.2(10.0)$ & $7.9(7.2)$ & $11.1(11.0)$ \\
\hline $\begin{array}{l}\text { PASI (baseline } \\
\text { BSA-PS } \geq \\
\text { 3\%), median } \\
\text { (range) }\end{array}$ & $\begin{array}{l}5.3 \\
(0.1-39.4)\end{array}$ & $\begin{array}{l}7.9 \\
(0.3-64.8)\end{array}$ & $\begin{array}{l}6.5 \\
(0.2-35.4)\end{array}$ & $\begin{array}{l}6.8 \\
(0.1-70.8)\end{array}$ & $\begin{array}{l}6.0 \\
(0.1-39.4)\end{array}$ & $7.3(0.1-70.8)$ \\
\hline
\end{tabular}

Conclusion: UPA efficacy was generally similar in patients with PsA with LSJ or HSJ, with both patient groups showing improvements in composite clinical endpoints and skin responses vs PBO.

REFERENCES :

[1] Mclnnes I, et al. Ann Rheum Dis 2020;79(Suppl. 1):16-17;

[2] Mease PJ, et al. Ann Rheum Dis 2020; Epub ahead of print.
Figure Proportion of patients (\%) achieving MDA, VLDA, PASDAS LDA, and PASDAS remission at Week 24 , and PASI 75 and sIGA 0/1 at Week 16 for UPA vs PBO, by arthritis subtype
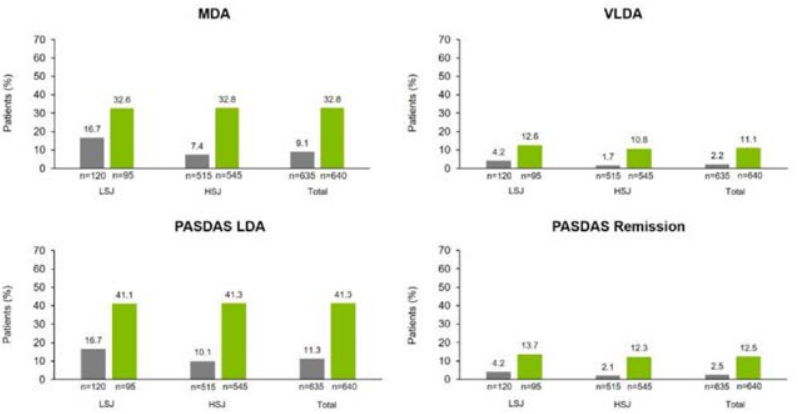

PASI 75
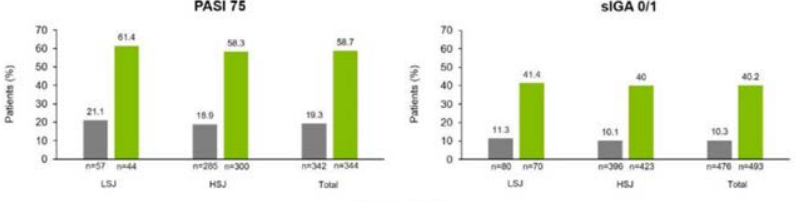

apiacoso = IUPA $15 \mathrm{mo}$

HSJ, high swollen joint count; LDA, low disease activity; LSJ, low swollen joint count; MDA, minimal disease activity; PASDAS, Psoriatic Arthritis Disease Activity Score: PASI, Psoriasis Area Severity Index; PBO, placebo; sIGA, static Investigator Global Assessment of Psoriasis: UPA, upadacitinib; VLDA, very low disease activity

Acknowledgements: AbbVie funded this study; contributed to its design; participated in data collection, analysis, and interpretation of the data; and participated in the writing, review, and approval of the abstract. No honoraria or payments were made for authorship. Medical writing support was provided by Grant Kirkpatrick, MSc of 2 the Nth (Cheshire, UK), and was funded by AbbVie.

Disclosure of Interests: Laure Gossec Consultant of: AbbVie, Amgen, Bristol-Myers Squibb, Celgene, Eli Lilly, Janssen, MSD, Novartis, Pfizer, Roche Sanofi, and UCB, Grant/research support from: AbbVie, Amgen, Bristol-Myers Squibb, Celgene, Eli Lilly, Janssen, MSD, Novartis, Pfizer, Roche, Sanofi, and UCB, Dafna D Gladman Consultant of: AbbVie, Amgen, Bristol-Myers Squibb, Celgene, Eli Lilly, Galapagos, Gilead, Janssen, Novartis, Pfizer, and UCB, Grant/ research support from: AbbVie, Amgen, Celgene, Eli Lilly, Novartis, Pfizer, and UCB, Erin McDearmon-Blondell Shareholder of: May own stock or options in AbbVie, Employee of: AbbVie, Philipp Sewerin Consultant of: AbbVie, Amgen, Axiom Health, Biogen, Bristol-Myers Squibb, Celgene, Chugai, Deutscher Psoriasis Bund, Eli Lilly, Fresenius Kabi, Gilead, Hexal, Janssen, Johnson \& Johnson, Medi-login, Mediri, Novartis, Onkowissen, Pfizer, Roche, Rheumazentrum Rhein-Ruhr, Sanofi, Swedish Orphan Biovitrum, and UCB, Grant/research support from: AbbVie, Amgen, Biogen, Bristol-Myers Squibb, Bundesministerium fuer Bildung und Forschung, Deutsche Forschungsgesellschaft, Deutscher Psoriasis Bund, Eli Lilly, Fresenius Kabi, Gilead, Hexal, Janssen, Novartis, Pfizer, Rheumazentrum Rhein-Ruhr, Roche, Sanofi, and UCB, Christopher T. Ritchlin Consultant of: AbbVie, Amgen, Celgene, Eli Lilly, Janssen, Novartis, Pfizer Sun, and UCB, Grant/research support from: AbbVie, Amgen, and UCB, Dai Feng Shareholder of: May own stock or options in AbbVie, Employee of: AbbVie, Apinya Lertratanakul Shareholder of: May own stock or options in AbbVie, Employee of: AbbVie, R Ranza Consultant of: AbbVie, Eli Lilly, Janssen, Novartis and Pfizer, Grant/research support from: AbbVie, Janssen, Novartis, and Pfizer, Lai-Shan Tam Consultant of: AbbVie, Boehringer Ingelheim, Eli Lilly, Janssen, Pfizer, and Sanofi, Grant/research support from: Amgen, Boehringer Ingelheim, GSK, Janssen, Novartis, and Pfizer, Antonio Marchesoni Consultant of: AbbVie, Bristol-Myers Squibb, Celgene, Eli Lilly, Janssen, MSD, Novartis, Pfizer, and UCB, Laura C Coates: None declared., Peter Nash Consultant of: AbbVie, Bristol-Myers Squibb, Celgene, Eli Lilly, Gilead, Janssen, MSD, Novartis, Pfizer Roche, Sanofi, and UCB, Grant/research support from: AbbVie, Bristol-Myers Squibb, Celgene, Eli Lilly, Gilead, Janssen, MSD, Novartis, Pfizer, Roche, Sanofi, and UCB.

DOI: 10.1136/annrheumdis-2021-eular.2127

\section{AB0551 \\ TREATMENT WITH IXEKIZUMAB FOLLOWING SECUKINUMAB FAILURE IN PATIENTS WITH PSORIATIC ARTHRITIS: REAL-LIFE EXPERIENCE FROM A RESISTANT POPULATION}

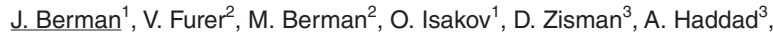
H. Matz ${ }^{4}$, O. Elkayam ${ }^{2}$. ${ }^{1}$ Sourasky Medical Center, Department of Medicine 'T', Tel Aviv, Israel; ' 2 Sourasky Medical Center, Department of Rheumatology, Tel Aviv, Israel; ${ }^{3}$ Carmel Medical Center, Department of Rheumatology, Haifa, Israel; ${ }^{4}$ Sourasky Medical Center, Department of Dermatology, Tel Aviv, Israel 
Background: Anti-IL17 agents, such as Secukinumab (SEC) and Ixekizumab (IXE) have been shown to be efficacious for the treatment of psoriasis and $\mathrm{PsA}^{12}$. In the field of psoriasis, there is growing evidence of a successful switching between the two anti-IL-17 agents in case of an insufficient response to one of the treatments ${ }^{3}$ There is no information on the efficacy of switching between anti IL17 agents in PsA. Objectives: To assess the clinical response to IXE in patients with PsA following SEC failure.

Methods: A retrospective observational study was conducted in two rheumatology centers in Israel, including PsA patients with a history of treatment with SEC, further treated with IXE for a minimum of 3 months. Lack of efficacy, loss of efficacy, and side effects over time were reported as a reason for switching to another anti-IL17 agent. The mean difference between the beginning of the follow up period and the different follow up points ( 6 and 12 months) was tested using a one-sample t-test. Time until treatment failure was estimated using Kaplan-Meier curves, and compared using the logrank test. Hazard ratios (HRs) and corresponding 95\% confidence intervals (Cls) were calculated using the Cox proportional-hazards model to test the association between each variable and the time to treatment failure.

Results: The study included 23 PsA patients (11\%/12 $\left.{ }^{\star}\right)$, mean age 58.7 years \pm 13.4 SD. Most patients $(n=20,86 \%)$ received $2+$ TNFi and 10 patients $(43 \%)$ received both TNFi and ustekinumab. Median number of biologics prior to SEC was 3 (IQR 2-4). There was a significant improvement in TJC at 6 and 12 months $(-2.16[-4.0,-0.3] ; p=0.025$ and $-1.69[-3.09,-0.28] ; p=0.022$, respectively). SJC was significantly improved at 6 months but not at 12 months (-2.68 $[-5.3,-0.04] ; p=0.046$ and $-1.50[-4.25,1.25] ; p=0.26$, respectively). CDAl score was significantly improved at 6 months $(-10.19,[-16.26,-4.1], p=0.002)$ and at 12 months $(-9.29[-14.8,-3.71], p=0.003)$ as was SDAl score $(-10.13[-16.4$, -3.8], $p=0.003$ and $-12.2[-17.1,-7.2], p=0.0002)$. At six months, PASI50 was achieved by $81 \%$ (13 patients), PASI 75 was achieved by $63 \%$ (10 patients), PASI90 was achieved by $50 \%$ ( 8 patients) and PASI 100 by $31 \%$ ( 10 patients). At 12 months, PASI50 and PASI75 was achieved by $57 \%$ (8 patients), PASI90 was achieved by $43 \%$ ( 6 patients) and PASI 100 by $21 \%$ (3 patients).

Over time, of the 23 patients treated with IXE, 15 patients $(65 \%)$ had experienced treatment failure, with a median treatment period of 8 months (IQR 6.5-13.5), of which $4(17 \%)$ had primary treatment failure and 11 patients $(48 \%)$ secondary treatment failure. Reasons for treatment cessation were: worsening psoriasis (4 patients $(27 \%))$, worsening peripheral arthritis (4 patients $(27 \%))$, both ( 7 patients $(47 \%)$ ), worsening of axial disease (2 patients (13\%)) and adverse events ( 1 patient, $6 \%$ ). Conclusion: patients after failure of multiple biologic treatments experienced significant response of peripheral arthritis and dermatologic disease on IXE after they had previously failed SEC. . However, in this refractory cohort of PsA, the effect was limited on time with $65 \%$ failure after a median time of 8 months. Within class switch from SEC to IXE is a plausible therapeutic option in PSA patients following secukinumab failure.

REFERENCES:

[1] Mease PJ, McInnes IB, KirkhamB, etal.NEnglJ Med.2015;373(14):1329-1339.

[2] NashP,KirkhamB,OkadaM, etal.LancetLondEngl.2017;389(10086):2317-2327.

[3] Bokor-Billmann T, Schäkel K. J Dermatol Treat. 2019;30(3):216-220

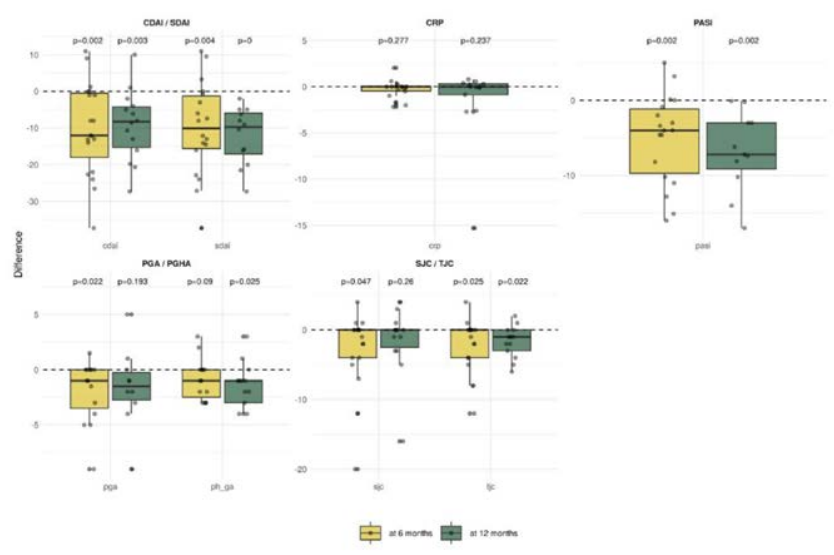

Disclosure of Interests: None declared.

DOI: 10.1136/annrheumdis-2021-eular.2186

\section{AB0552 PROBABILITY OF ACHIEVING TREATMENT TARGETS WITH APREMILAST MONOTHERAPY IN BIOLOGIC- NAIVE PSORIATIC ARTHRITIS PATIENTS IN ACTIVE WITH MODERATE AND HIGH BASELINE DISEASE ACTIVITY}

P. Nash ${ }^{1}$, S. Richter ${ }^{2}$, S. Jardon ${ }^{2}$, L. Teng ${ }^{3}$, J. A. Walsh ${ }^{4} .{ }^{1}$ Griffith University, Medicine, Brisbane, Australia; ${ }^{2}$ Amgen Inc., Global Medical Affairs, Thousand Oaks, United
States of America; ${ }^{3}$ Amgen Inc., Statistics, Thousand Oaks, United States of America; ${ }^{4}$ University of Utah, Rheumatology, Salt Lake City, United States of America

Background: Patients with psoriatic arthritis (PsA) in moderate disease activity (ModDA) who are naive to disease-modifying antirheumatic drugs (DMARDs) have a higher probability of achieving the Clinical Disease Activity Index for PsA (cDAPSA) treatment targets after receiving apremilast $30 \mathrm{mg}$ BID (APR) than those in high disease activity (HDA). In Europe, APR is indicated for the treatment of active PSA in adult patients who had an inadequate response or were intolerant to a prior DMARD therapy. Achievement of cDAPSA treatment targets with APR monotherapy in biologic-naive patients with PsA who had previously taken a max imum of 1 conventional synthetic DMARD (csDMARD) has not been evaluated.

Objectives: To assess the predictive value of baseline clinical disease status on achieving long-term cDAPSA treatment targets at Week 52 among biologic-naive patients with PsA in the phase $3 \mathrm{~b}$, randomized, placebo-controlled Assessing Apremilast Monotherapy in a Clinical Trial of Biologic-Naive Patients With PSA (ACTIVE). Methods: ACTIVE enrolled adults with PSA who had $\geq 3$ swollen and $\geq 3$ tende joints and were biologic naive with prior failure of a maximum of 1 csDMARD. In this post hoc analysis, we assessed the probabilities of achieving cDAPSA treatment targets of remission (REM; $\leq 4)$ or low disease activity (LDA; $>4$ to $\leq 13$ ) at Week 52 in patients randomized to APR and stratified by CDAPSA ModDA ( $>13$ to $\leq 27)$ or HDA (>27) at baseline. Patients with enthesitis at baseline in each stratum were analyzed separately.

Results: Of the 109 patients randomized to APR, 35 were in ModDA (32.1\%) and 71 were in HDA (65.1\%) at baseline (Table 1). For patients with ModDA vs HDA at baseline, swollen (4.6 vs 10.8) and tender (6.7 vs 21.7$)$ joint counts were lower, and the prevalence of enthesitis was lower (42.9\% vs $57.7 \%$ ) (Table 1). Patients in ModDA at baseline were estimated to be more than twice as likely to achieve treatment targets at Week 52 vs patients in HDA at baseline (Figure 1). Consistent with these results, a higher proportion of patients with ModDA + enthesitis at baseline achieved treatment targets at Week 52 than patients with HDA + enthesitis at baseline (58.9\% vs $32.8 \%$ ).

Table 1. Baseline Demographics and Disease Characteristics

\begin{tabular}{lll}
\hline Baseline cDAPSA Category & ModDA $(\mathbf{n}=\mathbf{3 5})$ & HDA $(\mathbf{n}=\mathbf{7 1})$ \\
\hline Age, mean (SD), years & $48.5(12.9)$ & $51.6(11.8)$ \\
Women, $\mathrm{n}(\%)$ & $20(57.1)$ & $36(50.7)$ \\
White, $\mathrm{n}(\%)$ & $34(97.1)$ & $71(100.0)$ \\
PsA duration, mean (SD), years & $4.5(4.6)$ & $3.8(4.5)$ \\
Enthesitis, $\mathrm{n}(\%)$ & $15(42.9)$ & $41(57.7)$ \\
SJC (0-66), mean (SD) & $4.6(1.6)$ & $10.8(4.3)$ \\
TJC (0-68), mean (SD) & $6.7(2.2)$ & $21.7(11.5)$ \\
PtGA (0-10 NRS), mean (SD) & $4.9(1.4)$ & $6.5(2.0)$ \\
PhGA (0-10 NRS), mean (SD) & $5.4(1.2)$ & $6.6(1.5)$
\end{tabular}

The $n$ represents the total sample. The number of patients with data available may vary. Not included are 3 patients in LDA at baseline. NRS $=$ Numeric Rating Scale; PhGA = Physician's Global Assessment of Disease Activity; PtGA = Patient's Global Assessment of Disease Activity; SJC = swollen joint count; TJC = tender joint count.

\section{Achievement of cDAPSA Treatment Targets at Week 52 With APR}

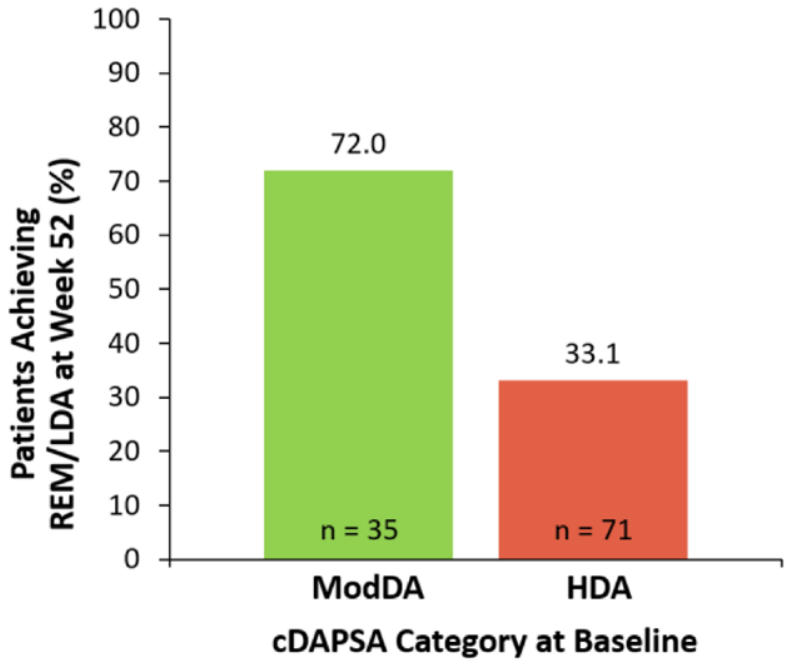

Patients randomized to apremilast $30 \mathrm{mg}$ BID at Week 0. Multiple imputation was used for missing data.

Figure 1. 